\section{THE EFFECT OF GRINDING THE SOIL ON ITS REAC- TION AS DETERMINED BY THE VEITCH METHOD}

\author{
By P. E. Brown and H. W. Johnson
}

Received April 16, 1915

In the course of some recent studies of Iowa soils, it became necessary to ascertain their reaction or need of lime and inasmuch as previous tests. had been carried out by the Veitch method and comparisons had indicated it to be quite satisfactory, it was decided to use the same method in this work.

It was soon noted, however, that the results which were being secured were in most cases the direct opposite of those obtained by previous tests of samples of the same soil types taken from approximately the same localities. For instance, practically all the samples from Bremer County were found to be basic in reaction, whereas previous tests of the soils of that county had shown that almost all were acid. The test had been carried out in exactly the same way in both cases. Every step in the operation and every detail in manipulation was carefully checked but no difficulties were encountered with the method. The soil samples were taken in the same way, and both lots were chosen as representative of soil types. Furthermore they were taken by the same man so that there was every reason to expect that the reaction of the samples would be very similar. At least it was felt that the same tendency of the soils to react acid or basic should have been observed with both lots of samples.

There was only one difference in the two lots of samples: the first was secured especially for acidity tests and the soils were tested in an unground condition, while the second lot was obtained in connection with the soil survey of the county and the samples were finely ground before being tested. This grinding was necessary in order to prepare the samples for the chemical analysis which was to be made of the soils.

It seemed probable, therefore, that the difference in the reaction of the two lots of samples was due to the grinding. The questions then arose-Does the grinding of soils increase their basicity according to the Veitch test? If so, what causes the production of a basic reaction?

In a critical study of the method which he devised. Teitch ${ }^{1}$ observed that the length of time the treated and dried soil was allowed to stand in contact with water had a considerable effect on the apparent acidity as determined by the method. He noted that when solution was allowed to go on from 48 to 72 hours the pink color with phenolphthalein was developed with less added lime water than when the solution was allowed to stand I 6 hours or less. The increase in basicity was so pronounced in some cases that soils which were acid when allowed to stand I6 hours gave a basic reaction upon standing 24 to 48 hours longer.

In discussing the cause of this increase in basicity, Veitch concluded that it was not due to the failure of

\footnotetext{
i J. Am. Chem. Soc, 26, 63i.
}

$\mathrm{CaCO}_{3}$ to go into solution in partially carbonated water in the shorter time and he suggested that the cause might probably be found in the slower solubility and hydrolyzation of the neutral lime compounds that are formed with the added lime water or to the solution and hydrolyzation of neutral compounds already present in the soil.

He called attention to the fact that in 1845 , Rogers Brothers ${ }^{1}$ showed that many of the common minerals, "particularly the zeolites and feldspars when reduced to fine powder and treated with carbon dioxide-free water, gave a more or less strong reaction with phenolphthalein." Since that time the solution of minerals in water has been studied by a large number of investigators $^{2}$ and it has come to be quite generally accepted that the observations of Rogers Brothers were correct. Minerals are known to be present in soils in considerable amounts, and their solution to proceed very slowly. The development of a basic reaction when soils are subjected to long standing in the lime-water test may, therefore, be due to the solution of silicates.

The directions for carrying out the Veitch test based on these experiments by the author of the method and numerous other investigators prescribe, therefore, that the samples shall stand only over night in contact with the water. In this way it is deemed that there is not sufficient time for the solution of any of the silicates in the soil to occur and make the test basic.

It seemed probable that the same reason which Veitch advanced for the development of a basic reaction by soil upon long standing with water might account for the production of basicity in a ground soil, that is, the solution and hydrolyzation of silicates.

As the point raised is of some interest and the question of the condition in which the soil should be when tested for acidity is of considerable importance, some tests have been carried out along this line. No previous investigations, as far as the authors are aware, have specified what the condition of the soil should be when the Veitch test is applied, and these results indicate that it is of importance because of the development of a basic reaction when soils are ground before being tested.

\section{EXPERIMENTAI}

In order to determine definitely whether grinding occasioned a development of basicity in soils, four samples of soil from Bremer County were secured and each sample was thoroughly mixed and divided into four portions. The first portion was unground and unsieved, the second was put through a 20 mesh sieve, the third through a 40 mesh sieve and the fourth portion through an 80 mesh sieve: grinding was done wherever necessary.

In the case of the Bremer fine sandy loam and the Carrington sandy loam very little grinding was necessary to put the soils through the 20 mesh sieve but considerable grinding was needed to put them

1 Am. J. Sci. and Arts, 5 (1845), 5.

2F. K. Cameron and J. M. Bell, Bur. of Soils, Bull. 30 (1905). 
through the 40 and 80 mesh sieves. With the other two soils, considerable grinding was required for them to pass the 20 mesh sieve.

Examining the results given in Table $I$, it is found that all the soils showed acidity when tested in an unground condition and all showed a basic reaction when they were ground and put through an 80 mesh sieve before being tested. With three of these samples enough basicity was developed, when the soils were ground to pass the to mesh sieve, to change the reaction from acid to basic. Even the slight grinding necessary to put the soils through the 20 mesh sieve reduced the lime requirements of two of the soils.

These results indicate clearly that grinding increases the basicity of soils and those normally having be expected, very little grinding being necessary to put the fine sandy loam through the 40 mesh sieve.

According to these results there seems to be a direct relationship between the sand content of the soil and the effect which grinding the sample exerts on the reaction by the Veitch test. The larger the amount of sand present and the coarser the condition in which it exists, the less grinding is required to alter the reaction of the soil according to the reitch test. Where the percentage of sand is low the effects of grinding are small although the influence in reducing the lime requirement of acid soils is still noticeable.

It is evident, therefore, that "silicates when finely ground lead to the development of a basic reaction" in soils and the observations of Rogers Brothers and

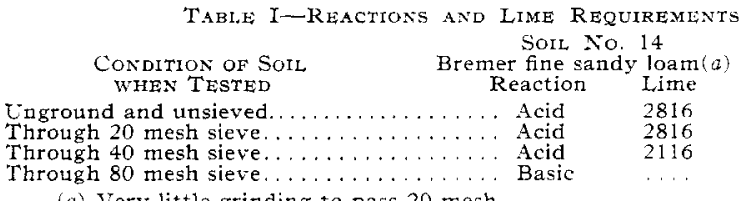

(a) Very little grinding to pass 20 mesh.

an acid reaction by the Veitch test may show a basic reaction.

In order to test the point further and also to ascertain to what extent the sand affected the development of a basic reaction when a ground sample was tested, five samples of the Lintonia series of soils from Iuscatine County, Iowa, carrying different contents of sand and all reacting acid in the natural condition were tested in the same way as the previous soils. The results appear in Table II.

The coarse sand needed a little grinding to put it through the 20 mesh sieve and this reduced the lime requirement somewhat but when ground and put

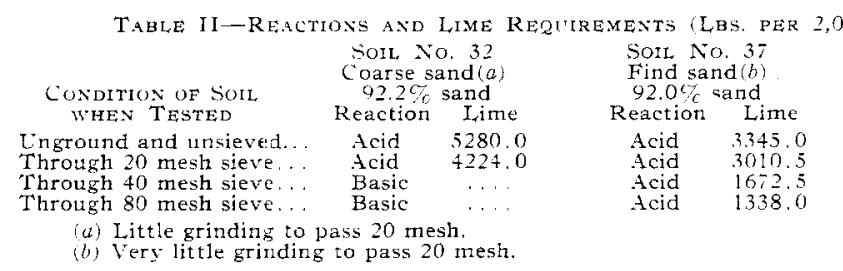

through the 40 mesh sieve the reaction became basic. Very little grinding was required to put the fine sand through the 20 mesh sieve and while more was required for it to pass the 40 and 80 mesh sieves the grinding was not sufficient to make the reaction basic; a graciual reduction in the lime requirement of the variously treated samples, however, was noted.

The Lintonia sand required no grinding to put it through the 20 mesh sieve and very little for the 40 . The lime requirement became less where the soil was put through the 40 mesh sieve and the reaction became basic when the 80 mesh sieve was used.

With both the coarse sandy loam and the fine sandy loam the lime requirement was changed by grinding, but the soils still tested acid even when ground to pass the 80 mesh sieve. The reduction in lime requirement was noted sooner in the coarse sandy loam as might

ER 2,000,000 Las. Of Surface Soll) of Fulr Saydy Loams Reaction Acid $\quad 3520$ Acid $\quad 3520$ Basic Soll No. 51 Soll No 57 coarse sandy loam $(b)$

(b) Considerable grinding to pass 20 mesh.

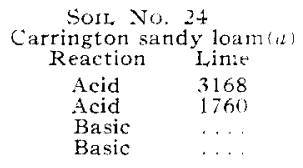

others, as noted above, are confirmed. Veitch's suggestion regarding the cause of the development of a basic reaction in the soil upon long standing with water is likewise confirmed.

In order to test soils for their reaction by the Veitch method it is obviously necessary, therefore, that the soil be in its natural condition and unground.

It may be argued that calcium silicate and other silicates lead to the production of basic compounds in the soil through the action of carbon dioxide produced in the decomposition of organic matter but this production of basic material is much too slow to remedy acid conditions in the soil and hence the soil

\begin{tabular}{|c|c|c|c|c|c|}
\hline \multicolumn{2}{|c|}{$\begin{array}{l}\text { Sorn No. } 18 \\
\text { Sand }(c)\end{array}$} & \multicolumn{2}{|c|}{$\begin{array}{c}\text { Sorn } \\
\text { Coarse sandy } 8 \\
\text { Coan }(a)\end{array}$} & \multicolumn{2}{|c|}{$\begin{array}{c}\text { Soll No. } 42 \\
\text { Fine sandy loam } \\
79.2 \% \text { sand }\end{array}$} \\
\hline Reaction & Lime & Reaction & Lime & Reaction & Lime \\
\hline Acid & 2.341 .5 & Acid & .3010 .5 & Acid & 5017.5 \\
\hline Acid & 2341.5 & Acid & 3010.5 & Acid & $501 \%$ \\
\hline Acid & 1672.5 & Acid & 1338.0 & Acid & 5017.5 \\
\hline Basic & $\ldots$ & Acid & 1338.0 & Acid & 4348.5 \\
\hline
\end{tabular}

reaction should be determined without consideration of the presence of silicates.

\section{SLMMARY}

The results of these tests lead to the following conclusions:

I-When acid soils are ground before being tested by the Veitch method the acidity is reduced and frequently the reaction becomes basic.

II-The derelopment of basicity increases with the grinding of the soil.

III-The increase in basicity depends upon the amount of sand present and is greater in coarse sandy soils than in fine sands.

IV-Coils should not be ground previous to testing their reactions by the Veitch method.

LABORATORY OF SOIL CHEMISTRY AND BACTERIOLOGY Iowa State Collage, Ames 